\title{
Mini Reviews@Virology
}

\section{Thoughts on Natural Medicinal Chemistry}

Xing Peng ${ }^{1 *}$, Meilan $\mathrm{Li}^{2}$

1.College of Chemistry and Chemical Engineering, Lanzhou University, Lanzhou City, Gansu province, 730000 , P.R. China.

2.Yanglinwei NO.2 Middle School, Xiantao City, Hubei province, 433021, P.R. China.

\begin{abstract}
Natural products, with novel structures and broad biological activities, are the main sources of drug lead compounds. Over years, natural products have made outstanding contributions to the fight against viruses. Herein, the article briefly shares some thoughts about natural medicinal chemistry as references for chemists and biologists.
\end{abstract}

Copyright@2012-2020 Published by Hong Kong Institute of Biologicals Standardization Limited. All rights reserved.

Article history:Submitted: 24/05/2019; Revised: 12/06/2019; Accepted: 18/06/2019

DOI: $10.21092 /$ jav.v8i3.111

Key Words: Natural products; Anti-viral leads; Pharmaceutical chemistry; Antibiotic

Abbreviations: NP, Natural Product; HTS, High-throughput Screening; CPE, Cytopathic Effect; EC50, Concentration for 50\% of Maximal Effect; RI, Reverse Transcriptase Inhibitor; II, Integrase Inhibitor; DARTS, Drug Affinity Responsive Target Stability; HR2, Heptad Repeat-2

\section{Introduction}

Natural products (NPs) had been the most significant source of potent drugs ${ }^{[1]}$, such as artemisin that revolutionized the treatment of malaria ${ }^{[2]}$. But the stagnation of antibiotic research and development in the past 20 years has been caused by numerous factors ${ }^{[3]}$. In addition to the low return on investment on pharm-aceutical economics, the more important factor is that pharmaceutical companies have reduced or even stopped their efforts to find drugs from NPs and turned to combinatorial

\footnotetext{
* Corresponding author, Major in Natural Product Chemistry

E-mail: pengsh16@lzu.edu.cn
} 
chemical-based drug discovery platforms ${ }^{[3]}$. However, the indisputable fact is that almost all antibiotics still in use are derivatives or analogues derived from NPs ${ }^{[3,4]}$. Even the new antibiotics that have been on the market in recent years or in clinical trials are basically analogues of known antibiotics.

However, the platform for discovery of antibiotics based on combinatorial chem-istry, high-throughput screening (HTS) and rational drug design have not been able to produce any new chemical synthesis antibiotics ${ }^{[5]}$. Therefore, it has become a consensus that finding lead compounds from NPs such as microorganisms is the only way to solve the problem of stagnant development of antibiotics ${ }^{[3,4]}$.

\section{Fragment Drug Design Based on Active NPs.}

The main task in the field of NPs research is to search for active compounds from secondary metabolites of plants or microorganisms. Many research groups focus on chromatographic separations mechanically, and then screen the activity after obtaining pure compounds. Or, more reasonably, target compounds can be rapidly isolated by activity tracing. But doing such work will make the job dependent on luck. For example, exploration of anti-HBV NPs has lasted many years, but no compounds have been marketed to treat the disease. It also suggests that we need to think about new methods to research NPs more efficiently.

To some extent, NPs are produced to meet the needs of plants themselves, rather than to solve human diseases. An important advantage of finding leads from NPs is that they provide an extremely large library of compounds to screen for. But plants are not themselves infected with HBV and so on, so it is not unusual failing to find suitable lead compounds to treat hepatitis B. But in a way, many effective molecules work by targeting proteins. Whether it's a person, a plant or a microorgnisms, there are always proteins with similar functions, but the differences between them make it difficult to use NPs directly. But protein residues and pockets can be similar, and we can use the specific skeletons and fragments of NPs to do some drug design.

From the data presented, the utility of NPs as sources of novel structures, but not necessarily the final drug entity, is still alive and well[6]. There are some drug entities which are totally synthetic but based on a NP pharmacophore. A obvious example would be the $\alpha$-blockers or $\beta$-agonists (selective or general) that are modeled upon the biogenic amines, and the subsets of dopamine receptor antagonists and serotonin receptor blockers derived from the base dopamine or serotonin structures (with modifications to aid in binding $)^{[6]}$, See figure 1 . 
<smiles>CNC[C@H](O)c1ccc(O)c(O)c1</smiles>

Epinephrine<smiles>CNC(C)C(O)c1ccccc1</smiles>

Ephedrine<smiles>CC(C)NCC(O)c1ccc(O)c(O)c1</smiles>

Isoprenaline<smiles>CC(C)NCC(O)COc1cccc2ccccc12</smiles>

$\mathrm{H}_{2} \mathrm{~N}$<smiles>CC(C)NCC(O)COc1ccc(CC(N)=O)cc1</smiles>

Atenolol<smiles>COCCc1ccc(OCC(O)CNC(C)C)cc1</smiles>

Metaprolol

Figure1: structures of analogues<smiles>Cc1cc(=O)n(C)c2c3c4c(cc12)c(C)cc(=O)n4CO3</smiles>

Deoxynybomycin<smiles>CC(C)=CC1C2C(=O)C3CCCN3C(=O)C2=C[C@]12C(=O)Nc1ccccc12</smiles>

Spriotryptostatin B<smiles>CCn1c(=O)cc(C)c2cc3c(C)cc(=O)n4c3c(c21)OC4</smiles>

1<smiles>COC(=O)C1N[C@@H](c2ccc(Br)cc2)[C@@]2(C(=O)Nc3ccccc32)[C@H]1c1cc(OC)c(OC)c(OC)c1</smiles>

2

Figure2: $\quad$ structures of NPs and their derivatives 
There are some natural-product-inspired synthetic compounds with potent pharm-acological effects. Appropriate chemical modification of the natural-product-derived fragments and scaffolds leads to the desired pharmacological activities. Compound 1 is an antibacterial agent for combating Staphylococcus aureus, coupled with compound 2 as the lead for the development of cytostatic $^{[7]}$, and see figure 2 .

\section{Discovery of new targets by NPs.}

As mentioned above, NPs provide a good library of compounds, and we can use some effective Chinese herbs to fish for target proteins. Based on proteomics, we may attain some unknown targets.

Amotsterol D is a ergostane-type steroid from Amoora tsangii with anti-HIV activity. The anti-HIV activity of Amotsterol D in MT4 cells against some RI- and II- resistant HIV-1 strains was evaluated. The results showed that Amotsterol D protected cytopathic effect (CPE) at similar $\mathrm{EC}_{50}$ values as that against the wild-type strain. These results also demonstrate that the inhibitory activity of Amotsterol D against HIV-1 seems to be not acting as a RI or II. A DARTS assay demonstrated that treatment with Amotsterol D protects a few proteins from proteolysis, identified as pyruvate kinase isoform M2 (PKM2), JUP, GAPDH, DSP, and etc. Taking other experimental results into consideration, it can be proposed that PKM2 might be the target. However, previously known to be associated with HIV-1, thus it can't be excluded that Amotsterol D might target additional proteins other than PKM2 ${ }^{[8]}$.

It's reported that triterpenoids, a class of natural products, antagonize this trimer-of-hairpins via its constitutive heptad repeat-2 (HR2), a prevalent-helical coil in class I viral fusion proteins. Triterpenoids inhibit the entry of Ebola, Marburg, HIV, and influenza A viruses with distinct structure activity relation-ships. Specifically, triterpenoid probes capture the viral envelope via photocross-linking HR2. Triterpenes cover the spiral surface of HR2 through their hydrophobic pentacyclic skeleton, which hinders the fusion of virus and cell membrane. HR1-HR2 affinity leads to the formation of trimer hairpin structure, which shows broad-spectrum antiviral activity and changes HR2 from "undruggable target" to "druggable target", which provides a new target and leading structure for the research and development of antiviral $\operatorname{drugs}^{[9]}$.

3. Inspiration from biosynthesis pathways of NPs

Natural products are a kind of compounds produced by organisms, which have certain synthetic pathways. But many chemists who work with natural products do not understand the advantages of biosynthetic pathways.

DARTS assay detected a few proteins not 
First, we can ponder on the structures of compounds through biosynthetic pathways, and even correct errors. As shown in the figure 3 , since the polypeptide portion consists of two amino acids condensed into a peptide bond, and the methylene group should not exist between the carbonyl and amino group.

Secondly, we can conduct biomimetic synthesis through biosynthetic pathways ${ }^{[10,11]}$, See Figure 4.

Finally, researching into regulable bio-synthesis can attain the target compounds more artificially ${ }^{[12]}$.<smiles>[R2]C1C(=O)N2CCC[C@]2(O)[C@@]2([R1])C[C@]([R1])(NC(=O)[C@H]3C=C4c5cccc6[nH]cc(c56)C[C@H]4[C@H](C)C3)C(=O)CN12</smiles><smiles>[R2]C1C(=O)N2CCC[C@]2(C)[C@]2(O)C[C@]([R1])(NC(=O)[C@H]3C=C4c5cccc6[nH]cc(c56)C[C@H]4[C@H](C)C3)C(=O)N12</smiles>

Figure 3: A examples of structural correction<smiles>O=CCCC=O</smiles><smiles>CNc1ccccc1</smiles><smiles>O=C(O)CC(=O)CC(=O)O</smiles>

\section{$\mathrm{CaCO}_{3}+\mathrm{HCl}$}

water

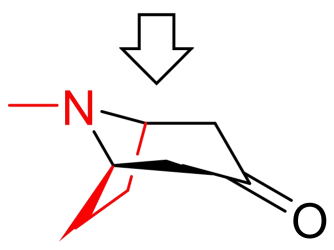

Figure 4: The classic synthesis in 1917 


\section{Conclusion}

Natural products and their molecular frameworks have a long tradition as valuable starting points for medicinal chemistry and drug discovery. China is rich in Chinese herbal medicine resources, which is our advantages. We should do more interesting work from the interdisciplinary perspective and make greater contributions to the research and development of new drugs.

\section{References}

[1]. Newman D J, Cragg G M. Natural products as sources of new drugs from 1981 to $2014[\mathrm{~J}]$. Journal of natural products, 2016, 79(3): 629-661.

[2]. Tu Y. The discovery of artemisinin (qinghaosu) and gifts from Chinese medicine[J]. Nature medicine, 2011, 17(10): 1217.

[3]. Martens E, Demain A L. The antibiotic resistance crisis, with a focus on the United States[J]. The Journal of antibiotics, 2017, 70(5): 520 .

[4]. Lewis K. Platforms for antibiotic discovery[J]. Nature reviews Drug discovery, 2013, 12(5): 371-387.

[5]. Vermote A, Van Calenbergh S. Small-molecule potentiators for conventional antibiotics against Staphylococcus aureus [J]. ACS infectious diseases, 2017, 3(11): 780-796.
[6]. Newman D J, Cragg G M, Snader K M. Natural products as sources of new drugs over the period 1981-2002 [J]. Journal of natural products, 2003, 66(7): 1022-1037.

[7]. Rodrigues T, Reker D, Schneider P, et al. Counting on natural products for drug design[J]. Nature chemistry, 2016, 8(6): 531.

[8]. Ge Y Z, Zhou B, Xiao R X, et al. A new class of HIV-1 inhibitors and the target identification via proteomic profiling $[\mathrm{J}]$. Science China Chemistry, 2018, 61(11): 1430-1439.

[9]. Si L, Meng K, Tian Z, et al. Triterpenoids manipulate a broad range of virus-host fusion via wrapping the HR2 domain prevalent in viral envelopes[J]. Science advances, 2018, 4(11): eaau8408.

[10]. Bedewitz M A, Jones A D, D' Auria J C, et al. Tropinone synthesis via an atypical polyketide synthase and P450-mediated cyclization $[\mathrm{J}]$. Nature communications, 2018, 9(1): 5281.

[11]. Robinson R. LXIII. - A synthesis of tropinone[J]. Journal of the Chemical Society, Transactions, 1917, 111: 762-768.

[12]. Zhang M, Hou X F, Qi L H, et al. Biosynthesis of trioxacarcin revealing a different starter unit and complex tailoring steps for type II polyketide synthase[J]. Chemical science, 2015, 6(6): 3440-3447. 